Acta Poetica $33 \bullet 1$

ENERO-JUNIO

$2012(87-115)$

\title{
Oratoria y performance en la Atenas clásica
}

\author{
Michael J. Edwards
}

En griego antiguo el término empleado para la "acción", una de las cinco partes de la retórica en la teoría retórica desarrollada, era hypokrisis, que también fue la palabra usada para hablar de "actuación" y no hay duda de que los ciudadanos atenienses, ya fuera sentados como jurados en los dikasteries atenienses o decidiendo sobre políticas en las reuniones de la asamblea, esperaban de aquellos que les hablaban que montaran una entretenida performance oratoria. Mucho se ha escrito sobre el tema en los últimos tiempos, y trato de adoptar un acercamiento diferente aquí al considerar once posibles indicadores de cómo se realizaban los discursos judiciales. Baso la discusión en el acrónimo "performance" y esbozo algunas inferencias a partir de los textos mismos. Los temas que se abordarán son: la importancia de la apertura del discurso (proemio) para dar la impresión correcta en los jurados; de qué manera los oradores que se encuentran en circunstancias particularmente difíciles pueden usar una forma alternativa de proemio llamada ephodos; el uso común de preguntas retóricas, por parte de los oradores, para lograr un acercamiento con el auditorio; la importancia de contar con una voz fuerte (phone) y las implicaciones de no poseer una; los temas interrelacionados de la oralidad, la estilística, el ritmo y la memoria (mneme, otra de las cinco partes de la retórica); la estratagema de dirigirse al oponente en segunda persona (apostrophe) como una forma de alejarlo de los jurados; algunos aspectos de la narración, que era un elemento clave de los discursos forenses; algunas referencias al reloj de agua (klepsydra) que cronometraba los discursos; finalmente, la importancia de dejar una buena impresión en los jurados al final del discurso (epilogos).

PALABRAs ClAVE: performance, oratoria ática, discursos judiciales, retórica clásica.

The ancient Greek for "delivery", one of the five parts of rhetoric in developed rhetorical theory, was hypokrisis, which was also the word for 'acting', 
and there is no doubt that Athenian citizens, whether sitting as jurors in the Athenian dikasteries or deciding policy in meetings of the Assembly, expected those who were addressing them to put on an entertaining oral performance. Much has been written on the subject in recent times, and I try to take a different approach here, considering eleven possible indicators of how lawcourt speeches were performed. I base the discussion on the acronym "performance" and draw inferences from the texts themselves. The topics covered are the importance of the speech's opening (proem) for making the right impression on the jurors; how speakers in particularly difficult circumstances might use an alternative form of proem called an ephodos; the common use by speakers of rhetorical questions to align themselves with the hearers; the importance of a strong voice (phone) and what the implications were if the speaker did not possess one; the interconnected subjects of orality, stylistic rhythm and memory (mneme, another of the five parts of rhetoric); the trick of turning to address one's opponent in the second person (apostrophe) as a means of alienating him from the jurors; some aspects of narrative, which was a key element of forensic speeches; references to the water-clock (klepsydra) which timed speeches; and finally the importance of leaving a good impression on the jurors at the end of the speech (epilogos).

KEYwords: performance, Attic Oratory, lawcourt speeches, classical rhetoric.

Fecha de recepción: 1 de diciembre de 2011

Fecha de aceptación: 29 de marzo de 2012 
Michael J. Edwards

University of Wales Trinity Saint David, Reino Unido

\author{
Oratoria y performance en la Atenas clásica \\ [Traducción del inglés de Luisa Puig \\ con la colaboración de Adán Brand]
}

Mucho se ha escrito en los últimos tiempos sobre la performance ${ }^{1}$ oratoria en Atenas; sólo mencionaré el excelente tratamiento que hace del tema Victor Bers en su Genos Dikanikon de reciente aparición. En el presente trabajo propongo una selección de inferencias que podemos aventurar con cierta certeza, a propósito de los discursos judiciales del corpus de la oratoria ática que llegaron hasta nosotros, sobre la manera como los litigantes pronunciaban esos textos. Al conformar esta selección, he tomado la palabra "performance" como un acrónimo, por lo que haré una exposición a partir de cada una de esas once letras. Si algo de lo que diga tiene algún mérito, lo debo al tutelaje que he recibido de Stephen Usher, a cuya memoria dedico este texto.

${ }^{1}$ El término "performance" ha sido acuñado en español con un sentido similar al del inglés de "representación", "puesta en escena". Aquí se emplea en un sentido más amplio de carácter lingüístico y retórico como: el uso de la lengua (la emisión de oraciones en determinadas situaciones comunicativas) y la ejecución o realización de un discurso por un sujeto hablante en una situación concreta [nota de la traductora]. 


\section{$P$ (proemio)}

Comencemos, pues, con la "P", que por supuesto es de proemio. Aristóteles, en su Retórica, traiciona su perspectiva esencialmente filosófica, al afirmar que

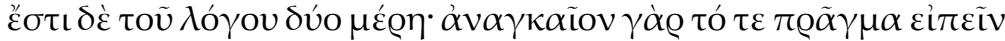

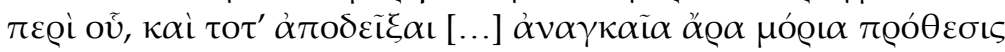

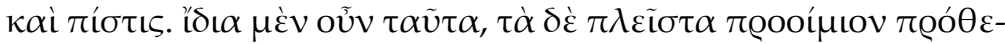

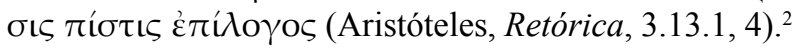

Un discurso tiene dos partes. Es necesario establecer el tema, y luego probarlo [...] De esta manera, las partes necesarias de un discurso son la exposición del caso y la prueba. Estas divisiones son apropiadas para todo discurso y, como máximo, las partes son cuatro en número - exordio, exposición, prueba, epílogo.

Aristóteles se justifica en cierta medida al admitir que "como máximo, las partes son cuatro en número: exordio, exposición [prothesis, a pesar de que discute a continuación la narración], prueba, epílogo"; pero cuando mucho se muestra tibio en relación con la importancia de los proemios:

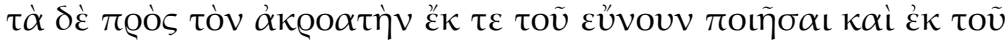

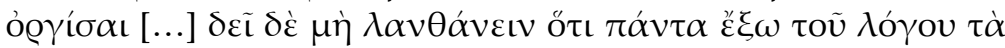

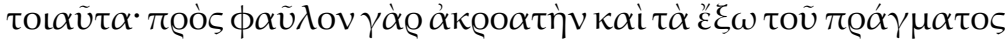

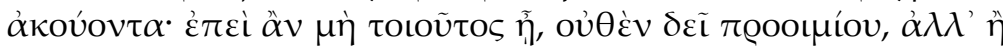

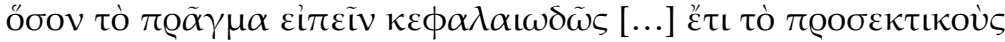

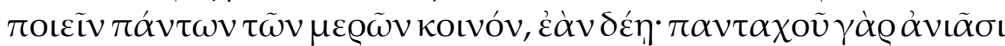

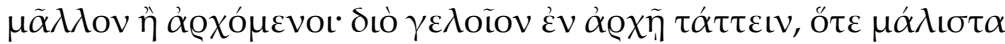

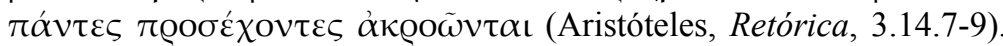

El objeto de una apelación al oyente es moverlo a la buena disposición o despertar su indignación [...] pero no debemos perder de vista el hecho

${ }^{2}$ Se hace notar al lector que las referencias a los textos griegos y latinos, en la bibliografía general, están ordenadas de acuerdo con los editores de dichas obras [nota de la editora]. 
de que todas estas cuestiones no se postulan, puesto que solo se dirigen a un oyente cuyo juicio es pobre y que está presto a escuchar lo que no viene a cuento; ya que si no se trata de un hombre de este tipo, no es necesario un exordio, salvo para hacer una narración sumaria del tema [...] Además, captar la atención de los oyentes es común a todas las partes del discurso, cuando es necesario; pues la atención suele perderse en cualquiera de las otras partes más que al principio. Así, pues, es ridículo colocar esto al principio, cuando todos escuchan con la mayor atención.

Aristóteles está en lo cierto, pero no es así como la mayoría de los escritores de discursos realizaban su tarea. Todo lo contrario, los logógrafos reconocían plenamente la importancia que tenía para sus clientes contar con un buen inicio. Un estudio a partir de una selección de los discursos forenses que ha llegado hasta nosotros, confirma el hecho esencial de que los oradores, a lo largo de los casi cien años que cubre nuestro corpus, reconocieron todos la importancia del proemio como un medio de captatio benevolentiae.

Debo inmediatamente subrayar que este no es, en ningún sentido, un análisis científico: forman parte de mi conteo, por ejemplo, secciones de longitud arbitraria, en lugar de considerar, digamos, el número de palabras que contienen. En la actualidad, las transcripciones legales en el Reino Unido se miden en términos de folios, compuestas de 72 palabras (o de cuatro líneas aproximadamente). Más aún, la división de los discursos no es un asunto preciso, y los estudiosos están a veces radicalmente en desacuerdo, incluso en lo que respecta a los proemios (como lo ilustro a continuación). Con todo, creo que han emergido algunos resultados interesantes. Así, los tres discursos de Antifón ( 1,5 y 6 ) tienen proemios de 4, 7 y 6 secciones respectivamente, aun cuando el más corto de ellos de hecho corresponde con un $12.9 \%$ del discurso total, el cual contiene 31 secciones en su totalidad. En promedio, los proemios de esos tres discursos, tal como los conocemos, representan el $9.6 \%$, pero debemos tener en cuenta que el final del sexto discurso parece haberse perdido y que el $7.3 \%$ del discurso 5 está posiblemente más cerca de lo que pudo haber sido la norma de Antifón. Puede o no ser entonces significativo que el discurso 1 , sobre el procesamiento de la madrastra por envenenamiento, sea claramente el caso más débil (algunos estudiosos han pensado, en efecto, que se trata de un discurso de práctica), con 
poca o ninguna evidencia de apoyo y sin testigos, por lo tanto, con una dependencia mayor de lo usual de las habilidades retóricas. Dicho esto, su epílogo contiene una sola sección (3.2\%), mientras que el epílogo del discurso 5, el caso de Herodes, consta de doce secciones, un final muy extenso que corresponde con el $12.5 \%$ de las 96 secciones del discurso en su conjunto. ¿Sintió Antifón que su cliente mitileno necesitaba más que nunca dejar una impresión en las mentes de los jurados antes de que votaran? Los proemios del amateur Andócides son más largos en los discursos 1 y 2 , diez y nueve secciones respectivamente, aunque diez secciones de las 150 del discurso de los Misterios corresponden con el $6.7 \%$, porcentaje ligeramente inferior a lo visto en Antifón. Pero nótese que nueve secciones de las 28 que componen el discurso Sobre su regreso equivalen a casi un tercio (32\%) del discurso, y las cinco secciones del epílogo a otro $17.9 \%$ - en otras palabras, cerca de la mitad de dicho discurso corresponde con el inicio y el final, lo que probablemente nos diga algo acerca de la presión que el exilio ejercía sobre Andócides. Lisias, en el juicio de Dionisio de Halicarnaso, era "el igual a cualquiera y superior a la mayoría" en la composición de proemios, y además, era "completamente original en cada discurso":

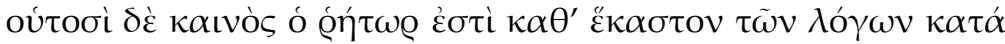

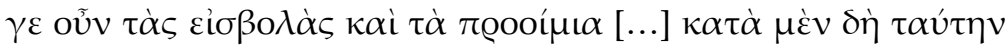

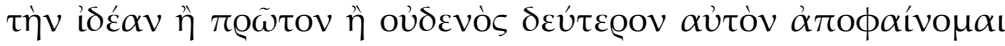
(Dionisio de Halicarnaso, Lisias, 17).

Pero Lisias es completamente original en cada discurso, por lo menos en lo referente al comienzo y la introducción [...] Por lo tanto, en esta parte del discurso lo declaro ser el igual a cualquier otro y superior a la mayoría.

Con todo, sus comienzos solo alcanzan alrededor de tres secciones en promedio. El discurso que destaca en este aspecto es el 19, Sobre la propiedad de Aristófanes, el cual, desde mi punto de vista, tiene un proemio de once secciones, aunque para Stephen Usher es de seis. De cualquier forma, se trata de un largo proemio para los estándares de Lisias, lleno de lugares comunes, y pareciera que Lisias sale de su estilo propio para presentar una imagen favorable de un cliente cuya hermana 
era la viuda de Aristófanes: él y su padre Nicofemo fueron ejecutados sin juicio alguno, después de servir con Conon, quizás por una fallida expedición a Chipre, así que es poco probable que los jurados hubieran tenido mucho tiempo para el orador. Usher señala el uso sin precedentes de $\chi \alpha \rho i ́ \sigma \alpha \sigma \theta \alpha$ r ("muéstrame la benevolencia") en la sección 2, lo que "contribuye a dar la impresión de un acusado congraciándose con el jurado" (Usher, Greek Oratory, 96 n., 145). Pero cabe señalar que el epílogo es muy breve (en mi opinión solo la sección 64), como si el ya largo discurso hubiera sido considerado suficiente y se pensara poco efectivo un extendido alegato final. Me limitaré a una consideración final sobre los proemios de dos oradores más. Esta se refiere a que no hay una disminución evidente de la importancia que se atribuye al proemio en Esquines y Demóstenes. Los tres discursos de Esquines tienen proemios de 8,11 y 8 secciones respectivamente, lo cual muestra un porcentaje relativamente bajo dada la longitud de dichos discursos; sin embargo, son proemios más largos que cualquiera de los vistos en Antifón, Lisias (salvo su discurso 19), Isócrates o Iseo. En el discurso Contra Ctesifonte, Friedrich Blass señaló, desde hace tiempo, el tono trágico del proemio, el cual ya había llamado la atención de los escoliastas (Die attische Beredsamkeit, 3.2, 208). Esto convenía al actor de la tercera parte, desde luego, pero contribuye a la dignidad que él asume en el discurso en su conjunto. Por último, Demóstenes normalmente tiene proemios de tres a cinco secciones, pero extiende su longitud a ocho secciones en sus dos más largos discursos: el 18 y el 19. La invocación a los dioses justo en el comienzo del discurso Sobre la Corona, que repite en la sección final del proemio, funciona como un contrapeso sobradamente efectivo en contra de la dignidad esquileana, y no es difícil imaginar a Demóstenes, a pesar de que criticara el histrionismo de Esquines, levantando los brazos y la mirada hacia el cielo, por lo menos en la primera ocasión.

\section{$E$ (ephodos)}

Las dificultades encaradas por el orador de Lisias 19 a las que me referí antes, llevaron en ocasiones a una forma diferente de proemio, llamada ephodos. Esta "aproximación oblicua" quizás no sea tan familiar para 
los estudiantes de retórica como debiera serlo, y veo que incluso en el excelente sitio web Silva Rhetoricae (http://rhetoric.byu.edu/) no tiene una entrada. La idea de un tipo diferente de proemio es discutida tanto por Anaxímenes en la Retórica a Alejandro (29, 1436-1437a), como por Aristóteles en su Retórica (3.15.3); dicha variante se emplea cuando el caso es percibido por el litigante como intrincado o difícil. A menudo se refiere a un litigante que, al ser sospechoso para los jueces a causa de algún mal comportamiento en el pasado, replica atacando a su oponente. Andócides, en el discurso 2, quizá representa el ejemplo más obvio del que ha sufrido suficiente en el pasado y cuyos oponentes son "o los hombres más estúpidos del mundo, o los peores enemigos de la ciudad" ( $(2)$, además de ser cobardes ( $(4)$. De nueva cuenta, Demóstenes abre su discurso Contra Lácrito con el comentario ofensivo:

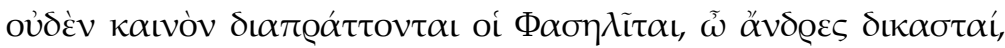

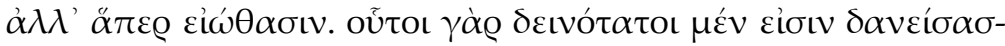

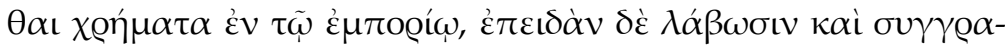

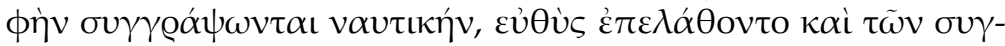

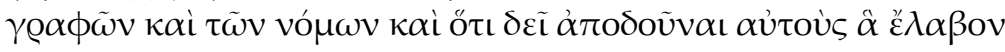
(Demóstenes, 35.1).

No es nada nuevo lo que están haciendo los faselitas, hombres del jurado; es lo que usualmente hacen. Son los hombres más terribles cuando piden dinero prestado en el puerto, y luego, después de conseguirlo y de concertar un acuerdo marítimo, se olvidan inmediatamente de los acuerdos escritos y de las leyes y de la necesidad de pagar lo que recibieron.

El orador Androcles entabló un juicio contra el faselita meteco Lácrito, como heredero del mercader Artemón, a quien, junto con su hermano Apolodoro, Androcles y un amigo le prestaron dinero. Lácrito presentó una contra denuncia (paragraphe) según la cual él no debía ser procesado por el procedimiento para casos mercantiles, probablemente basado en que no había un acuerdo escrito entre él y Androcles. Androcles tiene un acuerdo que fue dos veces leído pero era, desde luego, un acuerdo entre él y el fallecido Artemón y no con Lácrito. Como apunta MacDowell, el caso debió haber sido escuchado apenas fueron aprobadas las leyes mercantiles en 355 o poco tiempo después (Demosthenes, 
Speeches 27-38, 131), y pudo haber sido, por lo tanto, un caso de prueba. No conocemos el desenlace, pero Androcles pudo haber pensado que los jurados tendrían dudas (Lácrito habría sido el primero en hablar). El ataque al oponente (una forma de diabole) parece un elemento clave, y Dionisio de Halicarnaso tuvo sin duda razón al relacionar esta técnica con Iseo:

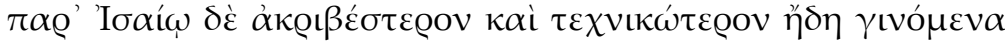

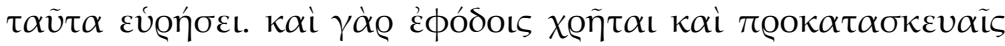

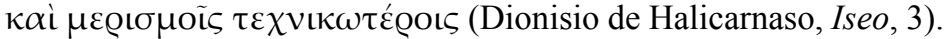

Pero el lector de Iseo encontrará que estos fueron manejados con mayor precisión y habilidad técnica. Él usa insinuaciones y anticipaciones y análisis de un tipo más estudiado.

Los discursos 1 y 3 contienen, desde su inicio, ataques al oponente (debo señalar que el discurso 3 no tiene un proemio claramente definido) y es interesante señalar que ambos contienen petitio principii o "peticiones de principio". El orador de 1 comienza con la exposi-

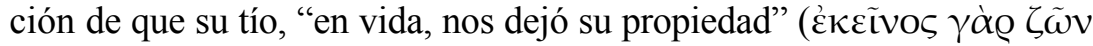

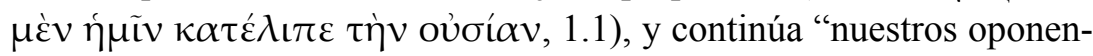
tes se han vuelto tan desvergonzados que están buscando privarnos de nuestro patrimonio [...] porque constataron nuestra extrema miseria"

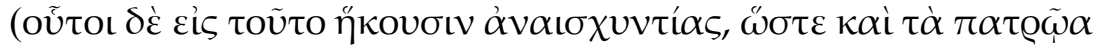

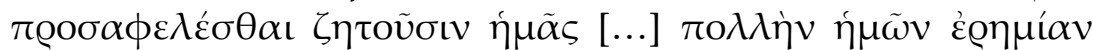

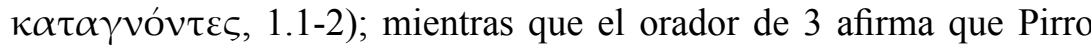

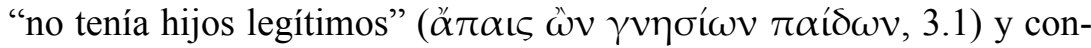
tinúa diciendo que Nicodemo, su oponente, "fue un completo desvergonzado en el testimonio que dio [en un juicio anterior], ya que tuvo la audacia de testificar que había dado a su hermana en matrimonio a

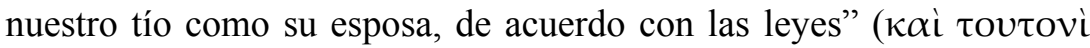

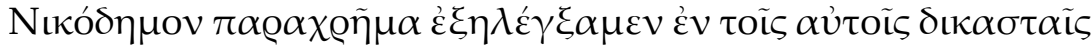

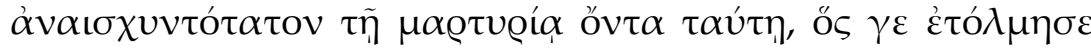

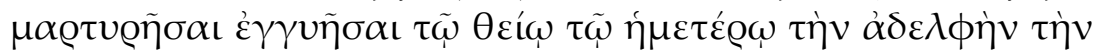

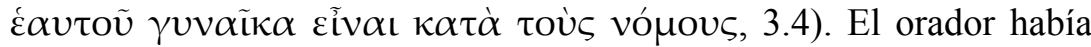
tenido éxito en el juicio anterior de Xenocles por falso testimonio, pero eso no garantizó que ganaría el caso actual. La audacia de este plantea- 
miento es evidente: si la performance de las palabras sale mal, el caso se pierde desde el principio. Andócides claramente lo hizo mal y tal vez de inmediato enajenó a los jurados —realmente no necesitamos el último análisis de Anna Missiou que, aun cuando es brillante me resulta a veces exagerado, acerca de la "oratoria subversiva" de Andócides para explicar su derrota en este caso. El cliente de Iseo en el discurso 1 también estaba claramente en contra de ese discurso, puesto que existía un testamento que él había admitido como genuino, que legaba los bienes a sus oponentes. Pero el ethos que le creó Iseo pudo haber sido más efectivo. El orador del discurso 3 parece tener una base más sólida, dado que ya ganó un caso en esta disputa, pero no hay proemio ni un epílogo real con alguna apelación emocional en este que es el discurso más largo de los que han sobrevivido, en lo que conforma el corpus de Iseo - de nuevo, la confianza pudo haber sido excesiva. Pero Demóstenes debió haberse sentido en un terreno más seguro cuando jugó la carta de la raza como medio para disfrazar la debilidad del caso de su cliente. Señalo, por último, que este método alternativo de apertura del discurso fue desarrollado en la teoría romana tardía, bajo el nombre de insinuatio. Cicerón, en De La Invención, hace una recomendación interesante:

deinde, cum lenieris eum, qui audiet, demonstrare, nihil eorum ad te pertinere et negare quicquam de adversariis esse dicturum, neque hoc neque illud, ut neque aperte laedas eos, qui diliguntur, et tamen id obscure faciens, quoad possis, alienes ab eis auditorum voluntatem (Cicerón, De La Invención, 17.24).

Luego, después de pacificar al auditorio, muestra que ninguno de esos cargos aplica a tu persona, y afirma que no dirás nada sobre tus oponentes, ni esto ni aquello, de manera que no ataques abiertamente a quienes son favorecidos y, sin embargo, trabaja imperceptiblemente, en la medida de lo posible, para ganar la buena voluntad del auditorio, lejos de tus oponentes.

Lo anterior no concuerda con lo que observamos del método griego, por lo que estoy de acuerdo con Usher (Greek Oratory, 129, n. 9) en que la identificación del ephodos con la insinuatio es hasta cierto punto engañosa. 


\section{$R$ (pregunta retórica)}

Una característica común a los diferentes oradores es el uso de la pregunta retórica (erotema). Es tan ubicua la pregunta retórica que podría no valer la pena hacer un comentario al respecto, sin embargo creo que es relevante en un trabajo sobre la performance dado que, ciertamente, fue una manera de atraer la atención de los oyentes: como se señala en la página Silva Rhetoricae, la pregunta retórica afirmaba o negaba enfáticamente un punto al enunciarlo como una pregunta, y generalmente tenía una dimensión emocional que podía expresar asombro pero también indignación o sarcasmo. Un ejemplo que se vio favorecido por retóricos posteriores viene del discurso Sobre la Corona, en donde Demóstenes ataca a Felipe de Macedonia:

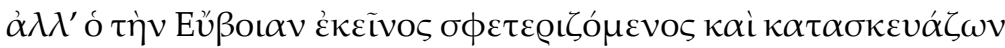

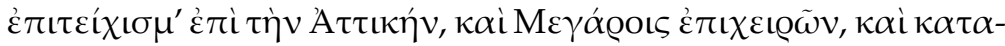

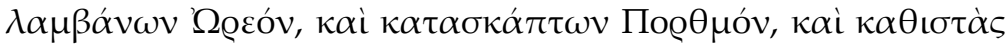

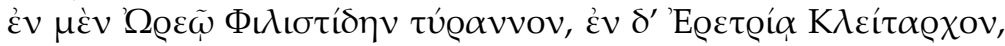

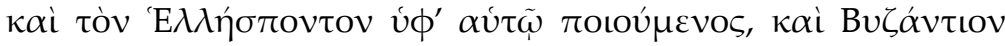

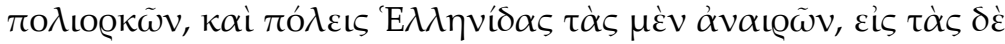

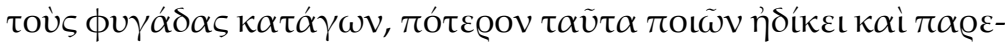

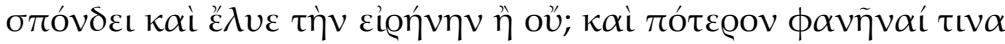

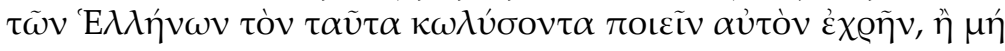
(Demóstenes, 18.71).

Pero el hombre que estaba apropiándose Euboea y preparándola como una fortaleza contra la Ática, que estaba atacando Megara y tomando Oreo, ocupando el Porthmo y erigiendo a Filistides como tirano en Oreo y a Clitarco en Eretria; subyugando al Helesponto, asediando a Bizancio, destruyendo algunas ciudades griegas y restituyendo a los desterrados en otras - ¿haciendo todas estas cosas estaba él o no actuando injustamente, rompiendo el tratado y violando la paz? Y ¿era o no la obligación de cualquier griego mostrarse para impedirle hacer estas cosas?

El autor de la Ad Herennium parafrasea la segunda pregunta:

et utrum aliquem exornari oportuit qui istaec prohiberet se fieri non sineret, an non? ([Cicerón], Rhetorica ad Herennium, 4.15.22). 
¿Y fue o no necesario emplear a alguien para impedir esos designios tuyos, y prevenir su cumplimiento?

Como ya mencioné en otro trabajo ("Isaeus the Rhetorician: a forgotten classic"), el uso extensivo de preguntas retóricas es una característica del método estilístico de Iseo, por el cual Dionisio $(I s e o, 13)$ lo compara con Demóstenes. La más larga sucesión de preguntas, siete, se encuentra en 8.28:

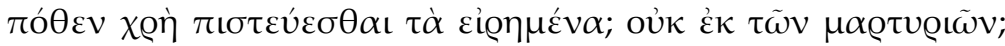

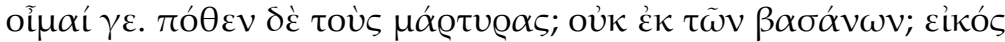

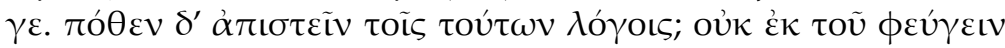

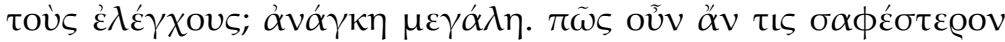

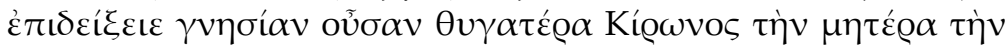

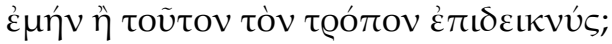

¿Por qué deberías creer lo que dije? ¿No es a causa del testimonio? Yo desde luego así lo creo. ¿Por qué deberías creer a los testigos? ¿No es a causa de la tortura? Es ciertamente razonable. ¿Por qué deberías desconfiar de las palabras de nuestros oponentes? ¿No es porque rehusaron las pruebas? Es una absoluta necesidad. ¿Cómo podría entonces cualquiera probar más claramente que mi madre es la hija legítima de Cirón, si no es de esta manera?

Hay una serie de seis preguntas en 7.40 y el discurso 3 tiene 39 preguntas en 80 secciones. También me llamó la atención, cuando trabajaba en los nuevos fragmentos de Hipérides del Palimpsesto de Arquímedes, que el empleo de las preguntas retóricas es un rasgo prominente en su método: cuento 18 preguntas en el texto preservado Contra Diondas (aun cuando, estrictamente hablando, no todas ellas son preguntas retóricas), con una serie de ocho en el siguiente pasaje:

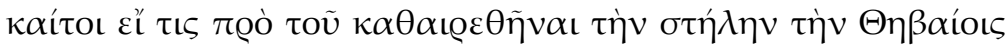

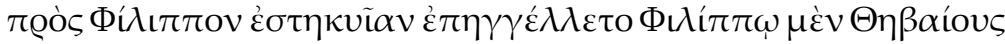

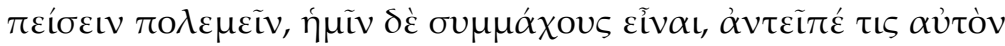

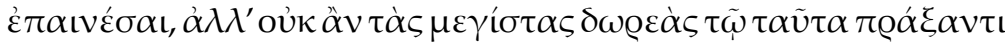

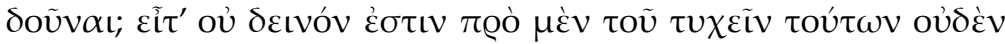

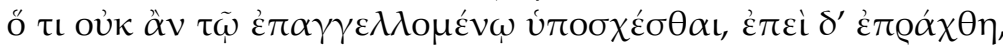




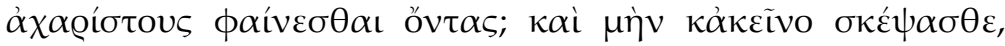

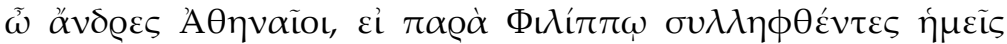

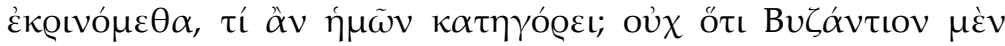

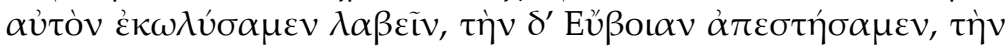

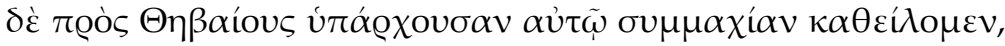

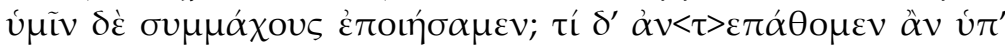

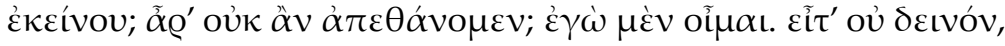

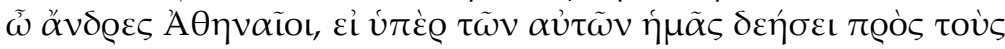

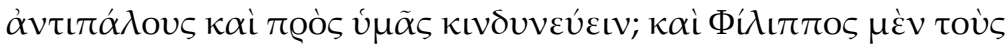

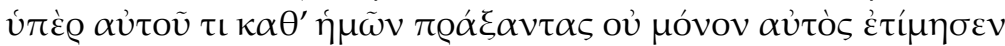

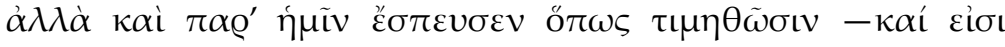

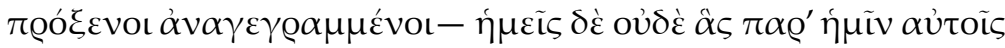

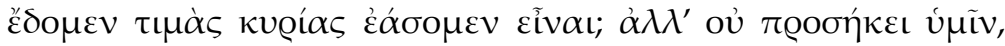

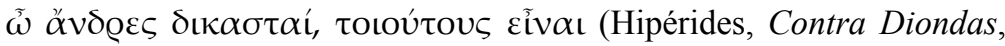
$137 \mathrm{v}-136 \mathrm{r})$.

$\mathrm{Y}$, sin embargo, si alguno, antes de la destrucción de la estela que fue erigida entre los tébanos y Filipo, se hubiese ofrecido para persuadir a los tébanos de ir a la guerra contra Filipo y ser nuestros aliados ¿se habría alguien opuesto a dirigirle alabanzas, cuando, en realidad, deberíamos proponer darle la mayor recompensa a aquel que hizo esto? Así entonces, ¿no es monstruoso prometerle absolutamente cualquier cosa, por anticipado, a la persona que hizo esta promesa, pero que una vez que lo consiguió no le muestren gratitud? Más aún, consideren también lo siguiente, hombres de Atenas. Si hubiéramos sido arrestados y sometidos a proceso ante Filipo, ¿cuál hubiera sido su cargo en contra nuestra? ¿No sería que le impedimos tomar Bizancio, e hicimos que Euboea se sublevara, y que destruimos la alianza con los tébanos haciéndolos aliados de ustedes? ¿Cuánto habríamos sufrido a cambio en sus manos? ¿Nos habrían dado muerte? Yo creo que sí. Entonces, ¿no es monstruoso, hombres de Atenas, que por las mismas acciones tendremos que enfrentar el peligro en la corte, ante el enemigo y ante ustedes? Y mientras que Filipo no solo personalmente honró a aquellos que emprendieron, en su nombre, cualquier acción contra nosotros, sino que además hizo todo lo que pudo para que nosotros los honráramos (y ya están oficialmente enlistados como nuestros proxenoi), ¿no permitiremos siquiera que los honores que concedimos entre nosotros mismos conserven su validez? Pero no es digno de ustedes, hombres del jurado, comportarse de esta manera. 
Nótese, de paso, el doble uso de la palabra "monstruoso" aquí — ¿estarían muchos de los miembros del jurado asintiendo con la cabeza, mostrando su acuerdo en este punto? Solicitar la opinión o el fallo del jurado o de la audiencia, lo que generalmente implica su común interés con el orador sobre el tema, es llamado anacoenosis y, evidentemente, es una forma de la acción potencialmente efectiva.

\section{$F(p h i)$}

Dado que el griego no posee la letra "f", hablaré ahora de una palabra que comienza con phi, phone (voz). Para Aristóteles:

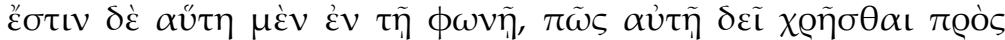

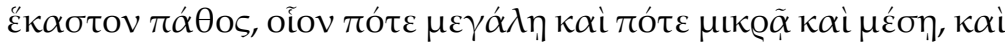

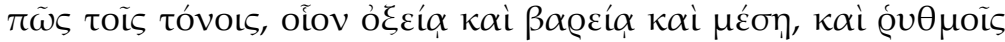

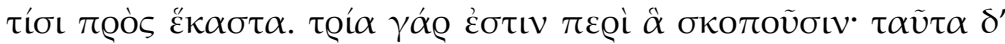

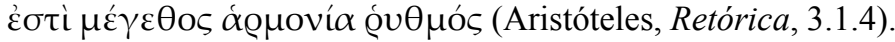

Ahora bien, la acción es un asunto de voz, entendida como la manera como debe usarse para cada emoción particular; cuándo debe ser fuerte, cuándo suave, cuándo intermedia; y cómo los tonos, esto es el agudo, el profundo y el intermedio deben emplearse; y qué ritmos se adaptan a cada tema. Dado que hay tres cualidades por considerar - el volumen, la armonía, el ritmo.

El tema es, en efecto, ampliamente tratado por Bers en su discusión sobre la acción y los pasajes representativos están ahí citados (Genos Dikanikon, 56 ss.): cómo la voz de Isócrates no era lo suficientemente fuerte para una carrera política; cómo Demóstenes tuvo que entrenar su voz y cómo atacó a Esquines por gritar, tal vez porque, en palabras de Chris Carey, su "impresionante voz al hablar [...] ponía particularmente nervioso a Demóstenes". Bers se centra en la voz alta y, partiendo de Aristóteles (Retórica, 3.7.4-5), considera que "efectivamente, los hombres a menudo hablaban fuerte o incluso gritaban, debido a una genuina emoción o por el simple miedo a no ser escuchados y que eso terminaba por perjudicar su caso". En particular se refiere a los litigantes amateur, 
los idiotai, y concluye que el ataque de Demóstenes a los gritos de Esquines, en Sobre la Corona 127, "es una explotación oportunista de un prejuicio general contra un estilo de habla, a la vez fuera de lugar en los tribunales, como reminiscente de los idiotai, quienes recurrían a los gritos". Ahora bien, podría ser que el tener una voz fuerte irritara a las personas, y dos de los clientes de Demóstenes están claramente preocupados al respecto:

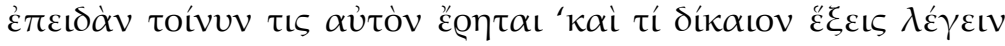

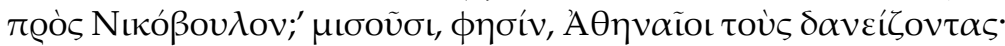

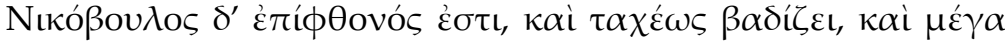

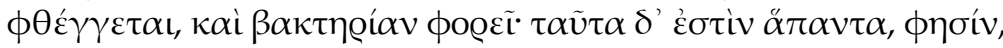

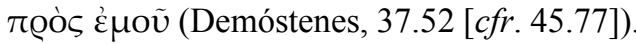

Cuando cualquiera le pregunta: “¿Qué justificación podrás dar para acusar a Nicóbulo?", él responde: "Los atenienses odian a los prestamistas. Nicóbulo es impopular; camina rápido, habla fuerte, y usa bastón. Todas estas cosas", dice, "están a mi favor".

Carey y Reid en su comentario al pasaje anterior (155-156) señalan que en la Ética de Aristóteles, los rasgos de un megalopsychos (magnánimo) incluyen "un andar lento, una voz profunda y una expresión

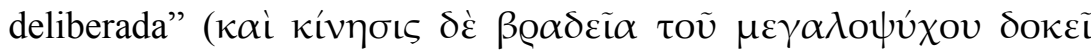

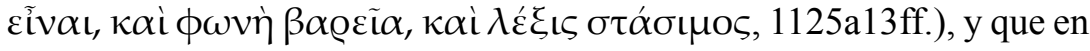
Teofrasto (Char. 4, cf. Cratinus fr. 374) hablar con una voz fuerte es la marca de un rústico sin modales. Pero, puedes hablar alto con una voz profunda en lugar de tonos estridentes y lo que, de hecho, Aristóteles dice en el pasaje de la Retórica (y Bers lo cita) es:

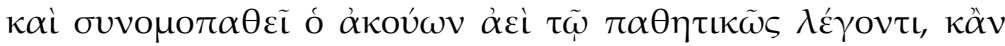

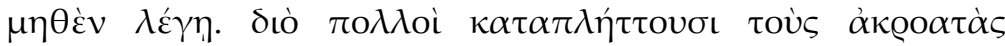

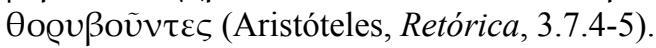

y el oyente siempre (aei) simpatiza con alguien que hable emotivamente, aun cuando no diga realmente nada. Es por eso que los hablantes suelen confundir a sus oyentes por el mero ruido. ${ }^{3}$

${ }^{3} \mathrm{O}$, como Bers, "muchos hombres destrozan a su auditorio con sus gritos". 
Aristóteles no dice que hablar fuerte lleve a la derrota (la implicación es quizás que, a menudo, ocurrió lo contrario) y, por supuesto, Esquines sí ganó dos de sus tres casos; mientras que la evidencia para los oradores amateur de Bers es, en realidad, inexistente. Una cosa adicional. A menudo tendemos a pensar en los oradores en un contexto político, hablando frente a miles de personas en el Pnyx, pero no deberíamos olvidar que los tribunales cubiertos en el ágora eran mucho más pequeños, incluso cuando albergaban a 500 jueces. Si, por ejemplo, el edificio A en la esquina noroeste del ágora era el Parabyston, este tenía 41 x $22 \mathrm{~m}$, con un área aproximada de $900 \mathrm{~m}^{2}$. Yo no llamaría a este un recinto masivo (y otros edificios en el área son más pequeños), y no estoy seguro, por lo tanto, de coincidir con la observación de Bers de que "la preocupación más obvia sería la de hablar lo suficientemente fuerte como para ser entendido en un gran espacio, frente a una audiencia bulliciosa, un reto que se ajusta a la historia de Demóstenes en la playa. Por extraño que parezca, hay muy poca evidencia directa de que un orador, hablando muy bajo, pueda ser escuchado". En el contexto del dicasterio, quizá esto no sea tan raro después de todo.

\section{O/R/M (oralidad, ritmo y memoria)}

Los tres temas siguientes están ligados entre sí: la oralidad, el ritmo y la memoria. Como todos sabemos, la Atenas clásica era en primer lugar, pero no exclusivamente, una sociedad oral, y no creo que haya duda alguna de que la expectativa de un hombre hablando en público fuera la de hacer una presentación oral y no escrita. Más aún, las sospechas respecto al arte del logógrafo parecen haber comenzado tempranamente, el fragmento del discurso de Antifón en su propia defensa ilustra lo anterior:

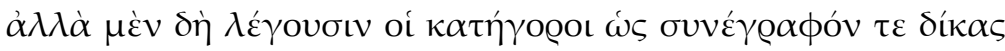

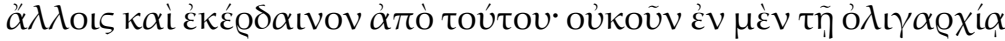

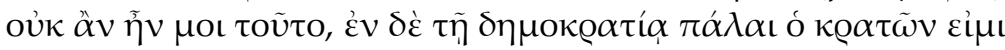

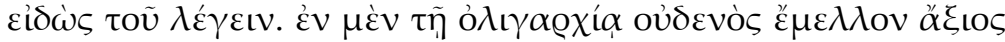

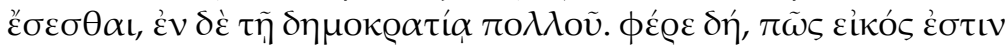

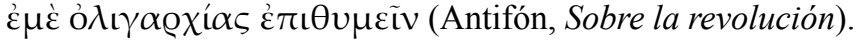


Mis acusadores dicen que componía discursos de otros para ser pronunciados en la corte, y que sacaba provecho de ello. Pero bajo una oligarquía no podría hacer esto, mientras que bajo una democracia he sido por mucho tiempo aquel con poder gracias a mi habilidad con las palabras. Yo no tendría valor alguno en una oligarquía, pero en una democracia soy muy valorado. Seguramente entonces, no sería probable que yo deseara una oligarquía. ${ }^{4}$

Pero, aún me pregunto si la expectativa siempre se cumplió plenamente. Tomemos, por ejemplo, el caso del mitileneo Euxiteo, en Antifón 5. Se trata, claramente, de un hombre relativamente joven, dado que sostiene (5.74-75) ser demasiado joven para conocer, de primera mano, las actividades de su padre en el tiempo de la revuelta mitilenea, la cual tuvo lugar no más de diez años antes del juicio. Pero sobre todo, el proemio de este discurso está cuidadosamente construido con un estilo grandioso e intrincado. El orador comienza con el topos de la inexperiencia, formulado antitética y quiásticamente:

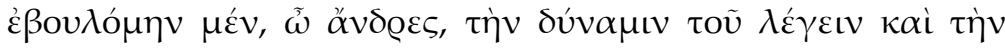

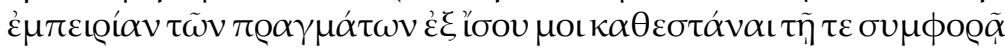

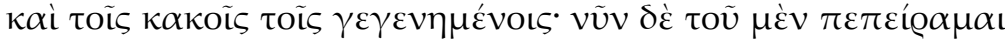

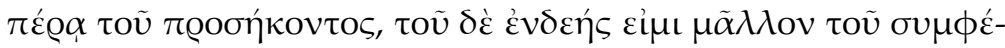
@ovтoৎ (Antifón, 5.1).

Quisiera tener la habilidad para hablar y la experiencia en cuestiones prácticas iguales a mis recientes problemas y desgracias, pero mi experiencia en estas últimas va más allá de lo que es correcto, mientras que mi deficiencia en la primera me deja en desventaja.

Como ciertos comentadores lo han señalado, la maestría de Antifón desmiente la afirmación de Euxiteo en cuanto a su inexperiencia, pero también me pregunto si Euxiteo realmente habría podido aprender de memoria el extenso discurso que ha llegado hasta nosotros en Antifón 5. Se lamenta de que fue llevado a prisión $(\S 17)$ y de que,

\footnotetext{
${ }^{4}$ Incidentalmente, el punto que aquí toca Antifón no se encuentra en Bers: "para descartar como improbable la acusación de que él sacaba provecho de los casos judiciales" (Genos Dikanikon, 14), cuando Antifón sostiene que como logógrafo exitoso no hubiera deseado una oligarquía; Bers no cita la última oración.
} 


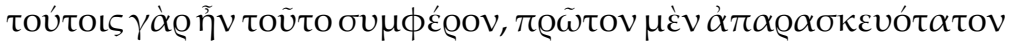

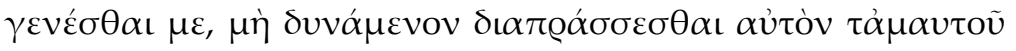

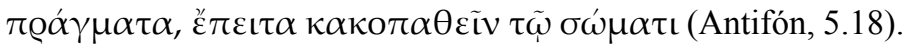

esto fue, por supuesto, ventajoso para ellos: primero no iba a estar preparado, dado que no podía atender mis propios asuntos y, segundo, iba a sufrir físicamente.

Cabe notar: "dado que no podía atender mis propios asuntos". Si esto es completamente cierto, uno se pregunta cómo pudo haber consultado a Antifón y aprendido el discurso. ¿Cuánto tiempo estuvo preso? Sospecho que no mucho. Había entonces, para un mitileneo, la aterradora expectativa de enfrentar una corte ateniense. Recordamos, con Bers, el fragmento de Eurípides que se refiere al miedo que paraliza a un hombre en un juicio por homicidio:

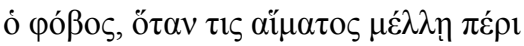

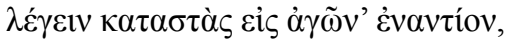

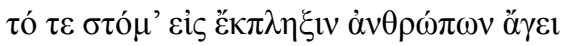

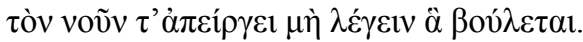

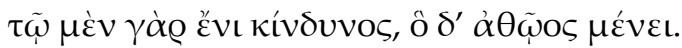

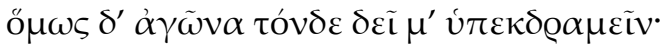

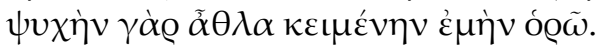

(Eurípides, frg. 88 Kannicht, [cf. Aristófanes, Las avispas, 944-948])

Cuando alguien viene a declarar en su juicio por homicidio, el miedo paraliza su lengua y su mente, y le impide decir aquello que desea. Para ese hombre hay peligro, mientras que el otro es invulnerable. Después de todo, debo eludir este juicio, puesto que veo que mi vida es la recompensa.

Dudo que Euxiteo fuera el único litigante que temiera por su futuro, e incluso oradores profesionales como Demóstenes en la embajada con Filipo o Cicerón en el juicio de Milo supuestamente no dieron lo mejor de sí frente a situaciones estresantes. ¿Sería posible entonces que algunos litigantes llevaran consigo al menos algún tipo de notas escritas? Muir escribe, en su edición de Alcidamas, que la reconocidamente 
confusa tradición de que el mismo Antifón fue el primero en tener un texto escrito para un discurso en la corte en su propio juicio en 411 "probablemente signifique [...] que en realidad llevaba consigo su texto a manera de recordatorio (¿en un juego de tablillas para escribir?, ¿en hojas de papiro sueltas?, ¿en un rollo de papiro? —ninguna de estas opciones resultaba muy fácil de usar para un orador), y que esto se volvió bastante común" (Muir, Alcidamas, xi). En otras palabras, las críticas al discurso escrito en Sobre aquellos que redactan discursos escritos de Alcidamas (quien, sin embargo, tiene que reconocer que los discursos improvisados están menos pulidos que los escritos) y la crítica de Platón en el Fedro (e.g. 275a), tal vez ocultaron la realidad de la situación en la corte para muchos litigantes. La alternativa para aquellos que creen en las presentaciones orales sin ningún apoyo escrito es que, en muchos casos, nuestros textos guardan poca semejanza (como en Antifón, 5) con lo que realmente fue dicho ese día. Michael Gagarin apunta al respecto que "no ayudaría al negocio de un logógrafo forense producir un mejor discurso para su publicación, que aquel que escribió para ser dicho en la corte, especialmente si el discurso pronunciado fue fallido" (Antiphon the Athenian, 21, n. 31). En respuesta a esto, uno podría citar el caso Pro Milone, en el que Cicerón supuestamente hizo justo eso: tal vez necesitemos un aristotélico punto medio.

En general, debe ser mucho más difícil aprender de memoria largos pasajes en prosa, que en verso. Sin embargo, para Aristóteles la acción debe tener un ritmo, como vimos en la cita anterior, y regresa a este tema en 3.8, con la importante salvedad de que "la prosa debe ser rítmi-

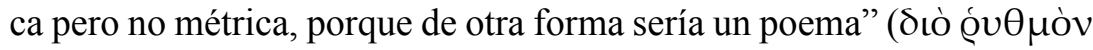

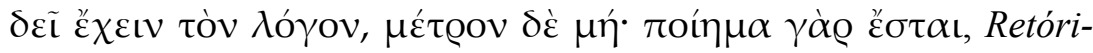
$c a, 3.8 .3)$. Aristóteles señala la importancia del ritmo yámbico, pero se centra en el peón, con un comentario interesante sobre la puntuación temprana:

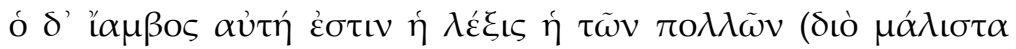

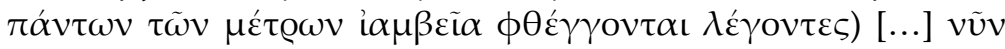

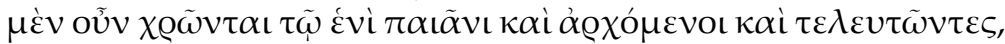

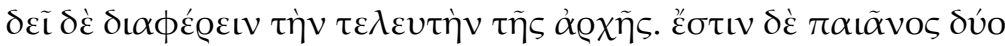

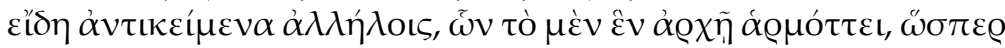




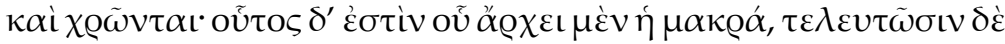

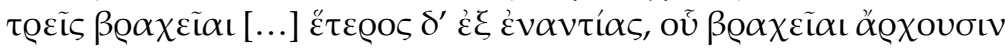

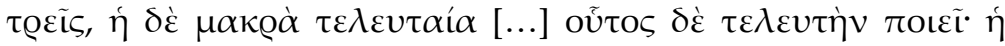

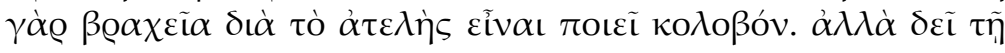

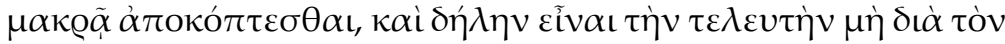

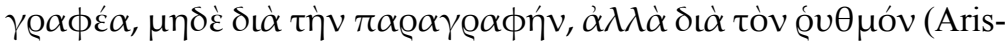
tóteles, Retórica, 3.8.4, 6-7).

El yambo es el lenguaje de la mayoría, por eso de todos los metros es el más usado en el discurso común [...] hoy en día, solo un tipo de peón es empleado tanto al comienzo como al final; el final, sin embargo, debe diferir del comienzo. Ahora bien, hay dos tipos de peones opuestos entre sí. Uno es apropiado para el comienzo, en donde de hecho suele usarse. Comienza con una sílaba larga y termina con tres cortas [...] El otro, por el contrario, comienza con tres sílabas cortas y termina con una larga [...] Este es un final adecuado, dado que siendo incompleta, la sílaba corta mutila la cadencia. Pero es necesario romper el periodo con una sílaba larga, y marcar claramente el final, no por el escribano o por el signo de puntuación, sino por el ritmo mismo.

El tema es abordado más ampliamente por Dionisio, en su Sobre la composición literaria (17-18), en donde propone escandir el comienzo de Sobre la Corona de la siguiente manera: "baquio $\left(^{-}-\right.$), espondeo $\left({ }^{-}\right)$, anapesto $\left({ }^{-}\right)$, espondeo, tres créticos $\left(^{-}\right)$, espondeo, antibaquio $\left({ }^{-}\right)$, baquio 'o, si se quiere, dáctilo', crético, dos peones (uno de cada tipo: ${ }^{-} \mathrm{y}^{-}$), 'moloso $\left({ }^{--}\right)$o un baquio, porque puede ser escandido de una u otra manera', espondeo, dos antibaquios, crético, espondeo, 'luego de nuevo otro baquio o un crético', crético, cataléctico". Tres observaciones: es interesante ver que el mismo Dionisio no está seguro de cómo escandir todos estos pies (lo que indica una de las dificultades que encara cualquiera que desee hacer esta tarea); la insistencia teórica de Aristóteles en la importancia del peón no se confirma con esta práctica de Demóstenes (en efecto, y de acuerdo con "la ley de Blass" (Die attische Beredsamkeit, 3.1, 105), Demóstenes evita una secuencia de más de dos sílabas cortas, con algunas excepciones) y ninguno de los pies es un yambo. Stephen Usher señaló, en la introducción de su Demosthenes (26), la "aún muy controvertida" naturaleza de la discusión sobre el ritmo en la prosa, y su análisis de la última oración del discurso resalta 
la preponderancia de las sílabas largas. Mucho trabajo adicional debe hacerse sobre el ritmo en la prosa, con una completa escansión del corpus, para poder ver qué patrones emergen y si ellos confirman la teoría de Aristóteles, en particular tal vez en puntos específicos de un discurso (en el comienzo y el final, si contiene un pasaje de narración vívida). En las cláusulas de apertura de Antifón 1, 5 y 6 , Andócides 1 y 2, Lisias 1 y 12 , por ejemplo, y en las palabras iniciales de la famosa narración sobre Elateia de Demóstenes, así como en sus pasajes del juramento de Maratón en Sobre la Corona, puedo ver solo un posible peón (si se escande

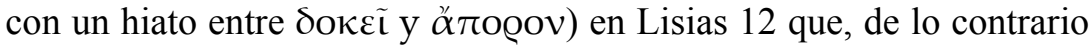

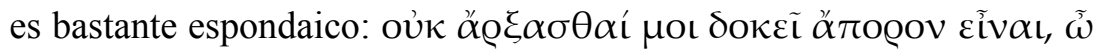

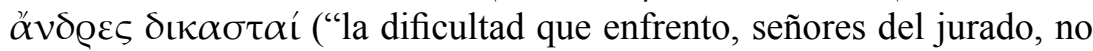
es cómo empezar"; aunque supongo que esto se aproxima a la idea de Aristóteles de que corto, corto, corto, largo es apropiado para el final de una cláusula). Dada la complejidad del ritmo, no estoy seguro de que esto hubiera sido una gran ayuda en la empresa de aprender de memoria largos discursos.

Sospecho que tampoco había técnicas mnemotécnicas muy desarrolladas en el periodo clásico. En las teorías retóricas posteriores, la memoria (mneme) se consideró, junto con la acción, una de las cinco partes de la retórica. Hay una mención temprana de la memoria en el Dissoi Logoi: "el más grande y mejor descubrimiento que se ha hecho para nuestras vidas es el de la memoria; es útil para todo, para fi-

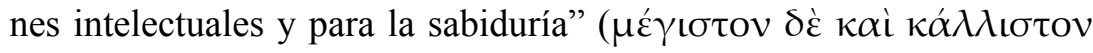

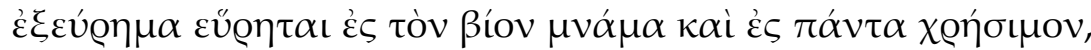

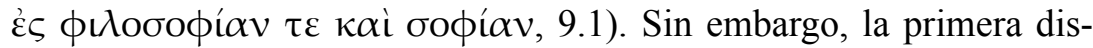
cusión sobre la memoria que ha sobrevivido, la encontramos en la $\mathrm{Ad}$ Herennium (3.16-24). El autor dice:

scio plerosque Graecos qui de memoria scripserunt fecisse ut multorum verborum imagines conscriberent ([Cicerón], Rhetorica ad Herennium, 3.23.38).

Sé que la mayoría de los griegos que han escrito sobre la memoria, han seguido el proceso de listar imágenes que corresponden a un gran número de palabras. 
No es para nada claro quiénes eran tales griegos: Aristóteles, por ejemplo, no habla de la memoria en su Retórica. Pero hay una escena interesante en el Fedro de Platón, cuando Sócrates persuade a Fedro de leer (y en efecto lee, en lugar de recitar de memoria) el discurso erótico presuntamente compuesto por Lisias. Fedro admite que no se ha aprendido el discurso de memoria (228d) y, de hecho, pregunta a Sócrates:

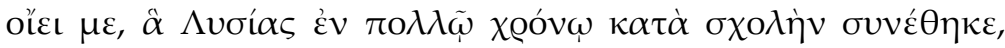

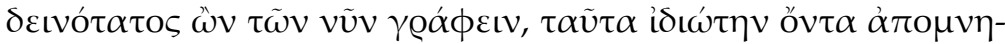

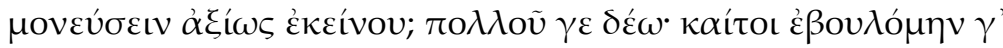

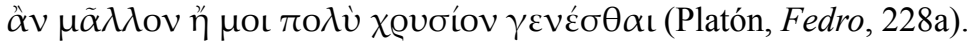

¿Crees que yo, un amateur (idioten), seré capaz de repetir de memoria, de una manera digna de Lisias lo que él, el más hábil de los escritores actuales, ha compuesto en el ocio durante un largo periodo de tiempo? Estoy lejos de ello; aunque me gustaría ser capaz de hacerlo, más de lo que me gustaría encontrarme con un montón de dinero.

Fedro, como interlocutor de Sócrates, no era un ateniense ordinario y sus palabras, probablemente, debieron ser aplicadas a muchos de los clientes de Lisias, así como a los litigantes ordinarios (idiotai) que forman la base del estudio de Bers.

\section{$A$ (apostrophe)}

A es para apostrophe, o "desviarse para dirigirse a alguien o algo distinto de la audiencia - usualmente al oponente de una manera hostil" (Usher, Greek Oratory, 364). Esta técnica de la performance es, desde luego, bastante común entre los oradores, aunque quizás no es tan frecuente como uno pudiera imaginar. Stephen Todd señala en su comentario a Lisias 6.50 (470), que "usar el vocativo como una forma para dirigirse al oponente [...] por su nombre, es una característica de los discursos de acusación, y a menudo un signo de que el hablante desea una confrontación [...] El uso equivalente del vocativo en los discursos de defensa es mucho menos común, pero se encuentra en 7.20, quizás como parte de una técnica de patrocinio para con los querellantes más 
jóvenes y de menor experiencia". El efecto debió ser, a veces, bastante considerable. Daré solo dos ejemplos. Como Usher hace notar (Greek Oratory, 137), Iseo 5 termina con uno de los más largos asesinatos de un personaje en la oratoria ática ( $\S 35-47)$. El fragmento comienza en tercera persona, pero repentinamente (en la sección 43), el orador Menéxeno se dirige a Dicaeogenes, y sacando ventaja de una relación familiar con los tiranicidas, termina con una pieza de diabole que no pudo haber dejado de causar la correspondiente impresión en los jurados:

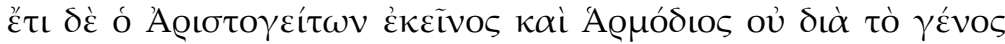

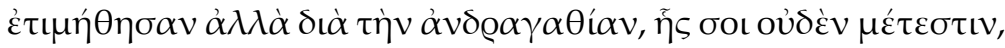
$\omega \tilde{\omega} \Delta \kappa \alpha \iota{ }^{\prime} \gamma \varepsilon v \varepsilon \varsigma$ (Iseo, 5.47).

Además, el gran Aristogitón y Harmodio no fueron honrados por su nacimiento, sino por su valentía, cosa que no compartes con ellos en absoluto, Dicaeogenes.

Pero regreso al alumno de Iseo para decir una última palabra sobre este tema. Un discurso en el que el acusado (o estrictamente hablando, el synegoros del acusado) se dirige continuamente a su oponente es, desde luego, el más famoso de todos. Demóstenes lanza, página tras página, una sarta de insultos personales a Esquines:

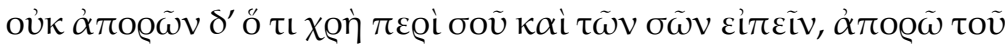

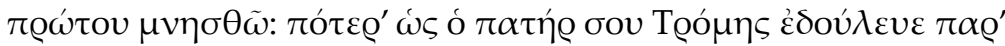

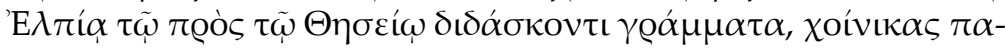

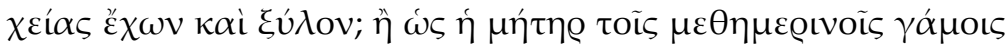

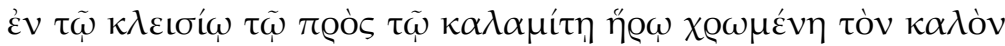

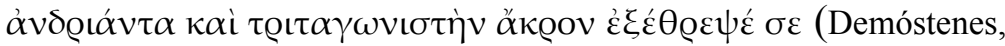
18.129).

No estoy frente a ningún dilema sobre lo que debo decir acerca de ti y de tu familia, solo sobre lo que debo mencionar primero. ¿Debería de ser que Atrometo, tu padre, fue un esclavo que llevó gruesos grilletes y un collar de madera, y que estaba al servicio de Elpias, quien tenía una escuela elemental por el Teseo? ¿O que tu madre era celebradora de bodas cotidianas en la choza cercana a Heros, el lugar de los curanderos, mientras te crió a ti, el fino, escultural, supremo actor de tercera parte? 
Finalmente llega al núcleo del asunto:

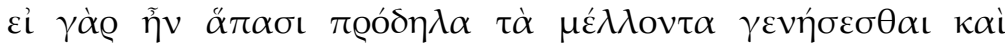

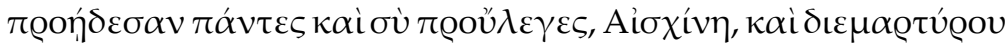

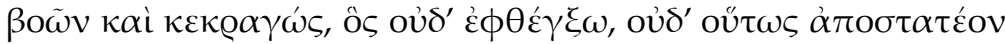

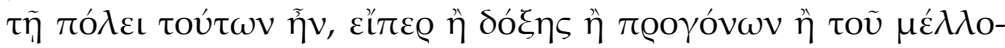

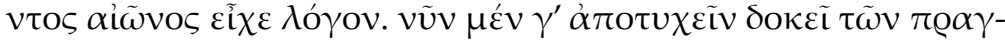

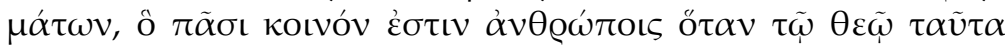

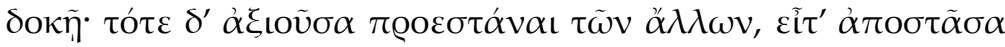

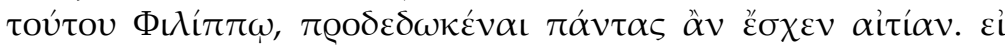

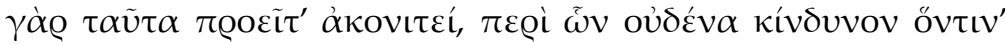

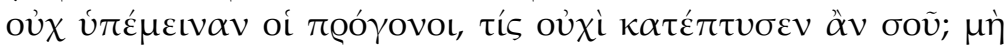

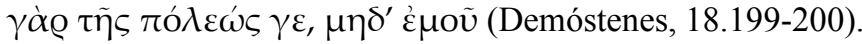

Si los acontecimientos futuros fueran claros para todos, y todos tuvieran conocimiento anticipado de ellos, y tú nos hubieras prevenido, Esquines, protestando con gritos y clamores (tú, que nunca emitiste ni siquiera un sonido), ni siquiera en aquellas circunstancias debía la ciudad haber abandonado sus políticas, si tenía alguna consideración por su reputación, por sus ancestros o por las generaciones venideras. Es cierto que, por como resultaron las cosas, parece haber fallado en sus empeños, lo que es el destino común de los hombres cuando Dios así lo decide. Pero entonces si después de sostener ser superior a otras ciudades, hubiera abandonado más tarde dicha pretensión, habría incurrido en el cargo de traicionar a todos con Filipo. Porque si te hubieras rendido sin ofrecer resistencia, lo que tus ancestros sufrieron todo riesgo imaginable para ganar, ¿quién no habría escupido sobre ti? ¡No sobre la ciudad y no sobre mí!

Nótese la onomatopeya kateptusen ('escupir sobre'). El alumno claramente aprendió bien.

\section{$N$ (Narración)}

Un elemento clave en los discursos forenses era por supuesto la narración (diégesis). Mucho se ha escrito sobre las técnicas narrativas en años recientes, de manera que me limitaré a hacer un par de observaciones. Como Aristóteles reconoció (Retórica, 3.13.3), la narración es 
en gran medida propiedad exclusiva de los discursos forenses, y recomienda que las narraciones en los discursos de defensa sean más breves (3.16.6). No estoy seguro de que así fuera en la práctica - Lisias 1 ciertamente no se ajustaría a este modelo-y, desde luego, para Dionisio:

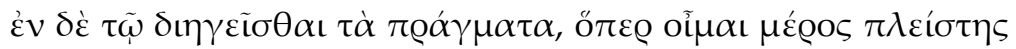

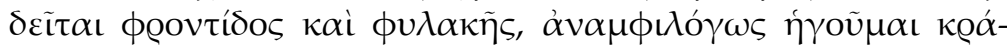

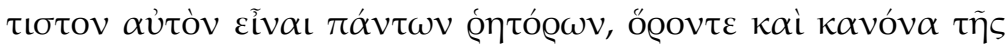

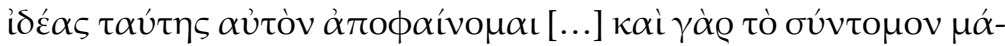

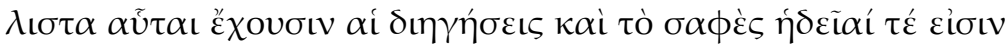

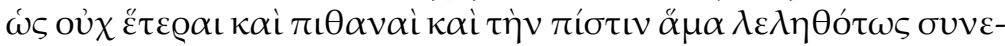

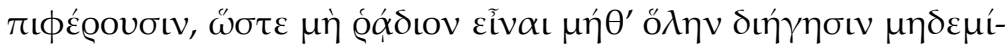

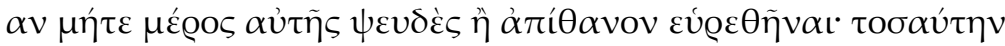

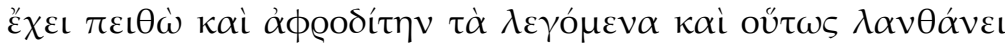

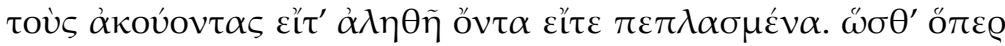

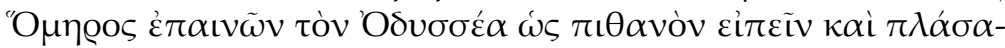

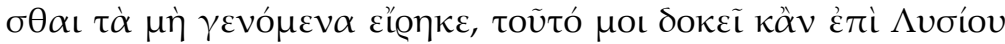

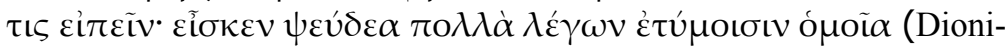
sio de Halicarnaso, Lisias, 18).

En la narración de los hechos, que considero como la sección que requiere mayor cuidado y reflexión, Lisias es, en mi opinión, incuestionablemente el mejor de todos los oradores. Declaro que él es un estándar y un modelo de excelencia en esta forma de oratoria [...] Estas narraciones suyas poseen las virtudes de la concisión y claridad en un grado elevado: además son singularmente agradables, mientras que sus poderes persuasivos son tales que introducen inadvertidamente la convicción por los sentidos de los oyentes. Es así difícil encontrar una narración que parezca falsa y poco convincente, ya sea en su totalidad o en alguna de sus partes, tal es el encanto persuasivo de la historia tal como la cuenta, y su poder para engañar a su audiencia sobre si es real o ficticia. Así que pienso que se podrían aplicar a Lisias las palabras con las que Homero alabó los poderes de persuasión de Odiseo, y su habilidad para fabricar ficciones:

El dijo muchas falsedades e hizo que sonaran verdaderas (Od. 19.203).

Pienso que los especialistas tienden a pasar por alto el hecho de que, después de describir lo que en la narración de Lisias lleva a Dionisio a formar su juicio, este último señala hasta qué punto Lisias tenía 
el poder para engañar — superado solo por el más maligno Iseo. Más aún, para muchos estudiosos esto describiría la narrativa de Lisias 1 a la perfección. Pero lo más importante para mis propósitos aquí es señalar que la performance de la sección narrativa del discurso tuvo que haber sido uno de los factores clave para determinar si el discurso sería exitoso o no. Me pregunto si por ello el estilo de las narraciones tiende a ser simple, no solo porque contar una historia con la inocencia de un niño es más efectivo, sino también porque podría ayudar al litigante a recordarla. Además, encuentro que la estructura teórica proemio/narración/pruebas/epílogo para nada se cumple en muchos discursos del corpus - Iseo rompe sus narraciones en casos complejos de herencia, pero Antifón y Andócides ya habían hecho algo similar mucho antes.

$C$ (Klepsydra)

Mi 'c' se convierte aquí en una ' $\mathrm{k}$ ' para klepsydra. Este era el reloj de agua que cronometraba los discursos. Ha habido algo de especulación sobre la exactitud de los relojes — sobre si los diferentes tamaños del conducto significaban distintas duraciones de tiempo, aunque como señala Todd (The Shape of Athenian Law, 132), eso no importa tanto, siempre y cuando las dos partes tuvieran, de hecho, el mismo par de klepsydrai en el juicio. Pero entonces me pregunto si el agua podría evaporarse en el calor del verano a una velocidad distinta a lo largo del juicio. Además, un litigante alega que el agua había sido distribuida de manera desigual por el arconte en un juicio anterior (Demóstenes, 43.89). Mi punto central, sin embargo, es la observación de que mientras que uno de los clientes de Demóstenes hace una observación sobre la cantidad de agua que queda en el reloj (41.30), tres de sus discursos $(36,38$ y 54$)$ terminan con las mismas palabras, aunque en el último se omite la oración final:

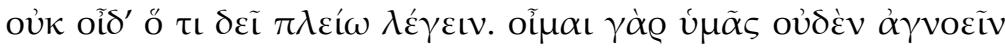

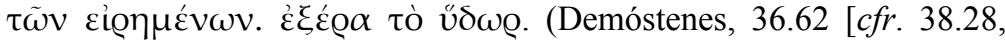
54.44]). 
No sé cuál es la razón por la que debería decir algo más; puesto que creo que nada de lo que he dicho se les ha escapado. Viertan el agua.

Este final es claramente entonces un topos y tal vez no deberíamos darle demasiada importancia. Pero en su conjunto, estos pasajes podrían reflejar una genuina dificultad para cronometrar la performance que, sospecho, no debió haber sido poco común, a pesar de lo bien preparados que pudieran estar tanto los discursos como los oradores.

\section{E (epílogo)}

Mi propia agua metafórica en este trabajo está por consumirse. La E será entonces para epílogo, que para Aristóteles se componía de cuatro partes:

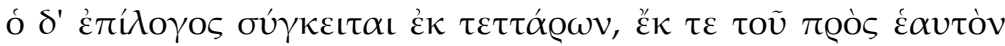

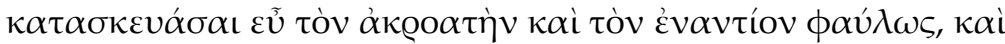

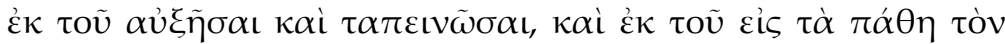

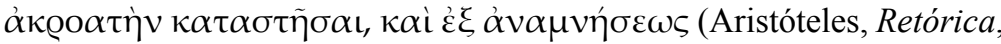
3.19.1).

El epílogo se compone de cuatro partes: para disponer al oyente favorablemente hacia uno y desfavorablemente hacia el adversario; para amplificar y desvalorizar; para excitar las emociones del oyente; para recapitular.

Me limitaré a señalar que las extensiones de los epílogos se mantuvieron bastante constantes en el siglo IV, en lo que se refiere a los discursos de corta y mediana longitud - usualmente no más de cuatro o cinco secciones. Antifón 5 y Andócides 1 (de doce y diez secciones, respectivamente) quizá reflejen el pensamiento de una época anterior, que puso mayor énfasis en el epílogo. Pero mientras que hay muchas variaciones en los epílogos que sobrevivieron y algunos oradores, como Eufileto en Lisias 1, terminan con una nota confiada o incluso estridente, muchos litigantes concluyen solicitando a los jueces que voten de acuerdo con la justicia y sus juramentos - un muy apropiado final, me atrevo a decir, para una performance retórica. 


\section{REFERENCIAS}

Bers, Victor, Genos Dikanikon. Amateur and Professional Speech in the Courtrooms of Classical Athens, Cambridge, Massachusetts/London, Harvard University Press, Center for Hellenic Studies, 2009.

Blass, Friedrich, Die attische Beredsamkeit, 1-3, Leipzig, G. B. Teubner, 1887. CAPlan, Harry, Rhetorica ad Herennium, Cambridge, Massachusetts/London, Harvard University Press/William Heinemann, 1954.

Carey, Chris, Aeschines, Austin, University of Texas Press, 2000.

Carey Chris y Robert A. ReID, Demosthenes. Selected Private Speeches, Cambridge, Cambridge University Press, 1985.

CAREY, Christopher, Michael Edwards et al., "Fragments of Hyperides' Against Diondas from the Archimedes Palimpsest", Zeitschrift für Papyrologie und Epigraphik 165 (2008), 1-19.

Edwards, Michael J., Isaeus, Austin, University of Texas Press, 2007.

Edwards, Michael J., "Isaeus the Rhetorician: a Forgotten Classic", en Lucia Calboli Montefusco (ed.), Papers on Rhetoric VII, Rome, Herder, 2006, 67-80.

Edwards, Michael J., Lysias. Five Speeches, London, Bristol Classical Press, 1999.

FreESE, John Henry, Aristotle, “Art” of Rhetoric, Cambridge/London, Harvard University Press / William Heinemann, 1926.

Gagarin, Michael, Antiphon the Athenian, Austin, University of Texas Press, 2002.

Gagarin, Michael, Antiphon. The Speeches, Cambridge, Cambridge University Press, 1997.

Gagarin, Michael y Douglas Maurice MacDowell, Antiphon and Andocides, Austin, University of Texas Press, 1998.

Henderson, Jeffrey, Aristophanes. II, Clouds, Wasps, Peace, Cambridge, Massachusetts/London, Harvard University Press/William Heinemann, 1998.

Hubbell, Harry M., Cicero, On Invention, Cambridge, Massachusetts/London, Harvard University Press/William Heinemann, 1949.

KanNicht, Richard, Tragicorum Graecorum Fragmenta 5.2, Euripides, Vandenhoeck \& Ruprecht, Göttingen, 2004.

MacDowell, Douglas Maurice, Demosthenes, Speeches 27-38, Austin, University of Texas Press, 2004.

Missiou, Anna, The Subversive Oratory of Andokides, Cambridge, Cambridge University Press, 1992.

Muir, J. V., Alcidamas. The Works and Fragments, London, Bristol Classical Press (Duckworth), 2001. 
Murray, Augustus Taber, Demosthenes. Private Orations XLI-XLIX, Cambridge, Massachusetts/London, Harvard University Press/William Heinemann, 1939.

Rackнам, Harris, Aristotle, Nicomachean Ethics, Cambridge, Massachusetts/ London, Harvard University Press/William Heinemann, 1934.

Rowe, Christopher, Plato, Phaedrus, Warminster, Aris \& Phillips, 1986.

TodD, Stephen C., The Shape of Athenian Law, Oxford, Clarendon Press, 1993.

TodD, Stephen C., A Commentary on Lysias. Speeches 1-11, Oxford, Oxford University Press, 2007.

Usher, Stephen, Demosthenes, On the Crown, Warminster, Aris \& Phillips, 1993.

Usher, Stephen, Dionysius of Halicarnassus. Critical Essays I, Cambridge, Massachusetts/London, Harvard University Press/William Heinemann, 1974.

UsHer, Stephen, Greek Oratory. Tradition and Originality, Oxford, Oxford University Press, 1999.

Silva Rhetoricae, The Forest of Rhetoric, $<\mathrm{http} / /$ /rhetoric.byu.edu/ $>$ [fecha de consulta: julio, 2012]. 